\title{
JOURNAL POLICY
}

PALEOBIOLOGY publishes original contributions of any length (but normally 10-50 manuscript pages) dealing with any aspect of biological paleontology. The emphasis should be upon biological or paleobiological processes and patterns. These include speciation, extinction, development of individuals and of colonies, natural selection, evolution, and patterns of variation, abundance, and distribution in space and time. Papers concerning research on recent organisms and systems are appropriate if they are of particular interest to paleontologists. Taxonomic papers are welcome if they have significant and broad applications. All manuscripts are to be in English. A guide to manuscript preparation is published in the first issue of each volume. Submission of a manuscript to PALEOBIOLOGY implies that it is not simultaneously being considered for publication by another journal.

PALEOBIOLOGY also welcomes submissions for Matters of the Record, which features up-to-date discussions of new discoveries, reviews of recent conceptual advances, and brief syntheses of important topics. In most cases, submissions will be limited to 4-6 manuscript pages with sufficient references. All submissions will be vetted for appropriateness and peer-reviewed prior to acceptance. Inquiries, proposals, and submissions should be directed to the editors.

\section{MANUSCRIPT ACCEPTANCE POLICY}

It is understood that, in return for publication, the journal has the non-exclusive right to publish the contribution and the continuing right, without limit, to include the contribution as part of any reprinting of the issue and/or volume of the journal in which the contribution first appeared by any means and in any format, including computer-assisted storage and readout, in which the issue and/or volume may be reproduced by the publisher or by its licensed agencies.

The appearance of the code at the bottom of the first page of each contribution in this journal indicates the copyright owner's consent that copies of the article (or of articles in back issues) may be made for personal use. For copying beyond that permitted by Sections 107 or 108 of the U.S. Copyright Law, this consent is given on the condition that the copier pay the stated per-copy fee through the Copyright Clearance Center, Inc. (P.O. Box 765, Schenectady, New York 12301). This consent does not extend to other kinds of copying, such as copying for general distribution, for advertising or promotional purposes, for creating new collective works, or for resale, and similar. 


\section{You can lose}

your valuable

\section{biological and}

geological

collections

through

improper storage!

\section{PERMANENT \\ AlR TIGHT}

SPECIMEN

\section{PRESERVATION}

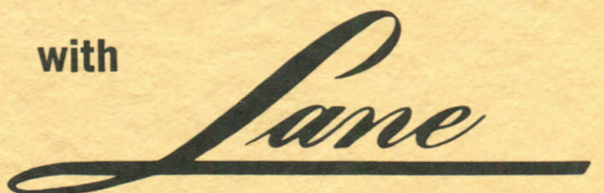

\section{SCIENCE CABINETS}

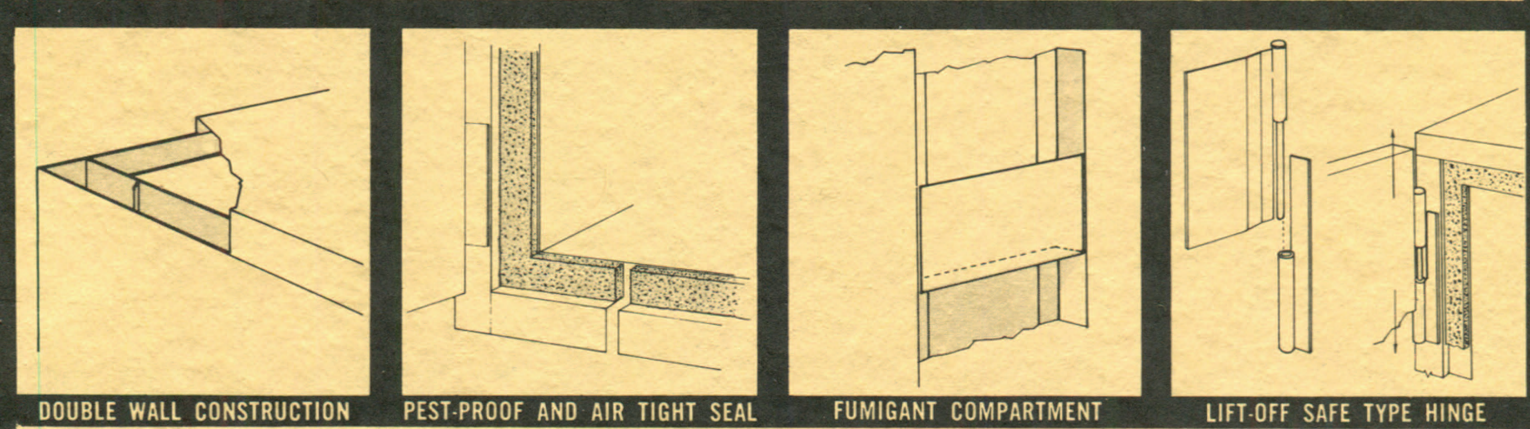

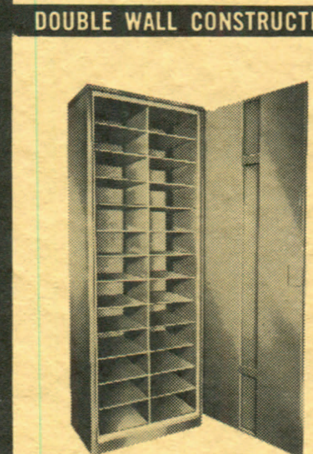

BOTANY

SPECIMEN

CABINETS

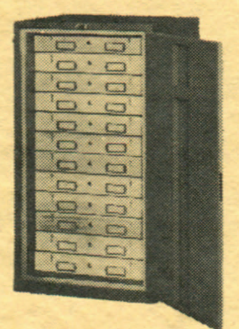

ENTOMOLOGY SPECIMEN CABINETS

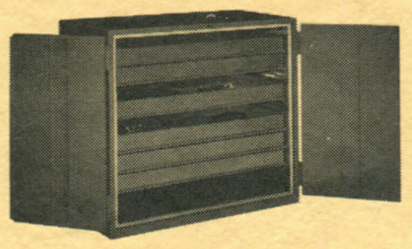

ZOOLOGY-ORNITHOLOGY SPECIMEN CABINETS

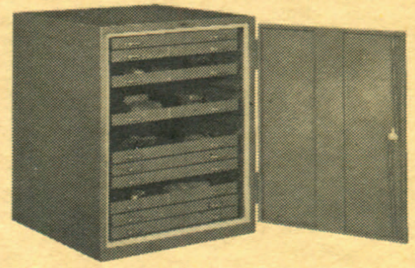

GEOLOGY-PALEONTOLOGY SPECIMEN CABINETS
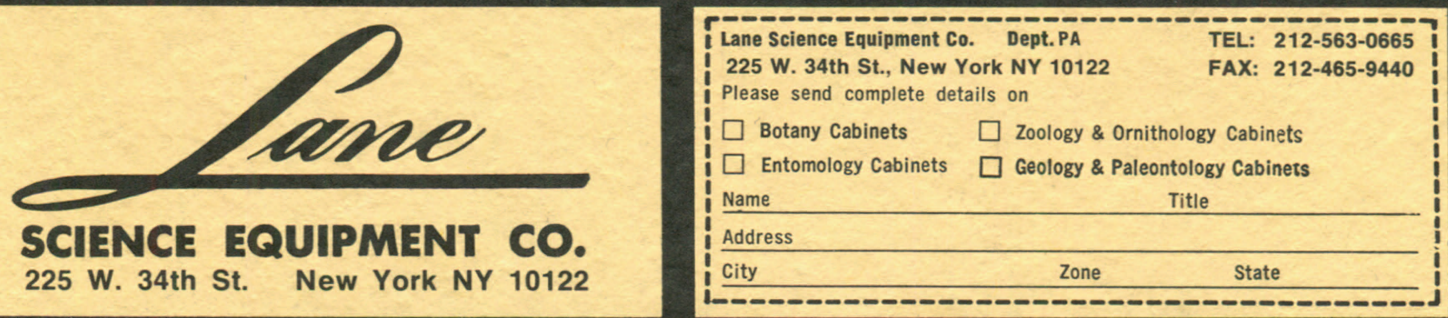